\title{
TÌNH HÌNH DINH DƯỡNG CỦA NGƯờI BÊ̂NH MẮC BÊ̂NH PHỔI TẮC NGHẼN MẠN TÍNH TẠI BỆNH VIỆN PHỔI TRUNG ƯO'NG NĂM 2021
}

\author{
Đỗ Nam Khánh ${ }^{1}$, Phạm Thị Mai Ngọc ${ }^{1}$, Chu Hải Đăng1, \\ Nguyễn Thị Thu Liễu ${ }^{1}$, Đỗ Mạnh Cầm ${ }^{1}$, \\ Vũ Văn Thành ${ }^{2}$, Nguyễn Viết Nhung ${ }^{2}$, Nguyễn Thanh Hà̀
}

\section{TÓM TẮT}

Mục tiêu: nghiên cứu thực hiện nhằm đánh giá tình trạng dinh dưỡng trên bệnh nhân mắc bệnh phổi tắc nghẽn mạn tínhtại khoa Bệnh phổi mạn tính Bệnh viện Phổi Trung ương từ tháng 12 năm 2020 đến tháng 5 năm 2021. Phương pháp nghiên cứu: Nghiên cứu mô tả cắt ngang trên 106 người bệnh được thu thập bằng cách chọn mẫu thuận tiện. Kết quả: Đối tượng có BMI trong giới hạn bình thường $(18,5 \leq$ BMI < 25) là 32,08\%. Đối tượng thấp cân (BMI < 18,5) là $58,49 \%$ và thừa cân, béo phì (BMI $\geq$ 25) là $9,43 \%$. BMI trung bình của ĐTNC là $18,1 \pm 3,13$ và $81,13 \%$ đối tượng nghiên cứu được xác định là có suy dinh dưỡng theo SGA. Trong 106 ĐTNC có 51 bệnh nhân $(48,11 \%)$ được chẩn đoán có tình trạng suy dinh dưỡng nặng (SGA-C), 35 bệnh nhân $(33,02 \%)$ được chẩn đoán suy dinh dưỡng mức độ nhẹ hoặc vừa (SGA-B) và 20 bệnh nhân $(18,87 \%)$ có tình trạng dinh dưỡng tốt (SGA-A). Kết luận: tỷ lệ bệnh nhân COPD bị suy dinh dưỡng chiếm tỷ lệ cao, do đó cần có biện pháp cải thiện tình trạng dinh dưỡng của người bệnh mắc bệnh phổi tắc nghẽn mạn tính tai Bênh viên Phổi trung ương.

Từ khóa: Tình trạng dinh dưỡng, bệnh phổi tắc nghẽn mạn tính, Bệnh viện Phổi Trung ương

\section{SUMMARY \\ NUTRITIONAL STATUS OF PEOPLE WITH \\ CHRONIC OBSTRUCTIVE PULMONARY DISEASE AT THE NATIONAL LUNG HOSPITAL IN 2021}

Objectives: The study was conducted to evaluate the nutritional status of patients with chronic obstructive pulmonary disease at the Department of Chronic Lung Diseases of the National Lung Hospital from December 2020 to May 2021. Research method: Cross-sectional descriptions of 106 patients were collected by convenience sampling. Results: Subjects with BMI within the normal range (18.5 $\leq$ $\mathrm{BMI}<25)$ was $32.08 \%$. Underweight (BMI < 18.5) subjects was $58.49 \%$ and overweight and obese subjects (BMI $\geq 25$ ) was $9.43 \%$. The mean BMI of the study population was $18.1 \pm 3.13$ and $81.13 \%$ of the study subjects were identified as having undernutrition according to SGA. In 106 studies, 51 patients

\footnotetext{
${ }^{1}$ Trường Đại họ Y Hà Nội

²Bênh viện Phổi Trung ướng

Chịu trách nhiệm chính: Đố Nam Khánh

Email: donamkhanh@hmu.edu.vn

Ngày nhận bài: 18/8/2021

Ngày phản biên khoa học: 20/9/2021

Ngày duyệt bài: 5/10/2021
}

$(48.11 \%)$ were diagnosed with severe malnutrition (SGA-C), 35 patients $(33.02 \%)$ were diagnosed with mild or moderate malnutrition (SGA-B) and 20 patients $(18.87 \%)$ with good nutritional status (SGA-A). Conclusion: the proportion of malnourished COPD patients accounts for a high proportion, so it is necessary to take measures to improve the nutritional status of patients with chronic obstructive pulmonary disease at the National Lung Hospital.

Keywords: Nutritional status, chronic obstructive pulmonary disease, National Lung Hospital

\section{I. ĐĂT VẤN ĐỀ}

Bệnh phổi tắc nghẽn mạn tính (COPD) là một căn bệnh phổ biến có ảnh hưởng đến sức khỏe toàn cầu. Theo Tổ chức Y tế Thế giới, ước tính đến năm 2030 số ca tử vong do COPD sẽ đứng thứ ba toàn thế giới [1]. Số ca mắc COPD tại Việt Nam vào năm 2010 là 385 triệu và có đển khoảng 3 triệu ca tử vong mỗi năm, tỷ lệ 7,1\% ở nam và $1,9 \%$ ở nữ từ 40 tuổi trở lên [1]. COPD đã trở thành gánh nặng y tế của các quốc gia và đòi hỏi nỗ lực toàn diện để kiểm soát hiệu quả [2].

Các triệu chứng phổ biến của COPD bao gồm khó thở liển tục cả khi nghỉ ngơi và tang lên khi hoạt động thế chất, ho mạn tính kéo dài kèm theo tăng tiết đờm. Năng lượng mất nhiều do hoạt động thở gắng sức khiến người mắc COPD có thể bị giảm cân không mong muốn dẫn đến suy dinh dưỡng nặng, suy kiệt. Vì vậy chế độ dinh dưỡng đóng vai trò hết sức quan trọng trong điều trị bệnh phổi tắc nghẽn mạn tính [3].

Nắm rõ đặc điểm tình trạng dinh dưỡng của người bệnh giúp bác sĩ dinh dưỡng cũng như bác sỹ điêuu trị sớm đưa ra can thiệp dinh dưỡng kịp thời giúp người bệnh cải thiện tình trạng dinh dưỡng từ đó hỗ trợ hiệu quả điều trị bệnh. Với mong muốn đánh giá tình trạng dinh dưỡng để kịp thời có những khuyến nghị phối hợp nâng cao hiệu quả điều trị bệnh phổi tắc nghẽn mạn tính, chúng tôi thực hiện đề tài này với mục đích đánh giá tình trạng dinh dưỡng của người bệnh mắc bệnh phổi tắc nghẽn mạn tính tại bệnh viện Phổi Trung ương năm2021.

\section{II. ĐỐI TƯỢNG VÀ PHƯƠNG PHÁP NGHIÊN CỨU}

2.1. Đối tượngnghiên cứu (ĐTNC): Nghiên cứu được tiến hành trên người bệnh mắc bệnh phổi tắc nghẽn mạn tính tại Khoa Bệnh 
phổi mạn tính, Bệnh viện Phổi Trung ương.

2.2. Thời gian và địa điểm nghiên cứu

- Địa điểm nghiên cứu: Khoa Bệnh phổi mạn tính - Bệnh viện Phổi Trung Ương

- Thời gian tiến hành nghiên cứu: Từ tháng 12/2020 đến tháng 5 năm 2021.

\subsection{Phương pháp nghiên cứu}

- Thiết kế nghiên cứu: Nghiên cứu mô tả cắt ngang

- Cỡ mẫu nghiên cứu: Áp dụng công thức tính cõ mẫu:

$$
\mathrm{n}=\mathrm{Z}^{2} 1-\mathrm{a} / 2 . \frac{p(1-p)}{(p \cdot \varepsilon)^{2}}
$$

Trong đó: $\mathrm{n}$ là cõ̃ mẫu nghiên cứu; p: tỷ lệ bệnh nhân COPD có nguy cơ dinh dưỡng của nghiên cứu trước $p=0,68$ [4]; $\varepsilon$ : mức sai lệch tương đối giữa tham số mẫu và tham số quần thể. Trong nghiên cứu này chúng tôi chọn $\varepsilon=$ 0,173; a: mức ý nghĩa thống kê $=0,05 \rightarrow Z(1-$ $a / 2)=1,96$ : tra từ bảng $Z$ ứng với giá trị $a=$ 0,05 . Thay các giá trị vào công thức trên, nghiên cứu tính được cỡ mấu tối thiểu là 100. Trên thực tế, nghiên cứu đã thực hiện trên cỡ mẫu cuối cùng là 106.

\section{- Phương pháp chọn mẫu}

Mẫu nghiên cứu được lựa chọn theo phương pháp chọn mẫu thuận tiện, tất cả bệnh nhân được nhập viện trong thời gian tiến hành nghiên cứu, thỏa mãn các tiêu chuẩn lựa chọn đều được chọn vào nghiên cứu. Trong 159 bệnh nhân tại khoa Bệnh phổi mãn tính từ 25/1/2021 đến 16/4/2021, số ĐTNC đủ điều kiện tham gia nghiên cứu là 106.

\section{- Biến số nghiên cứu}

Thông tin chung của đối tượng nghiên cứu: tuổi, giới, trình độ học vấn, tình trạng hút thuốc lá

Chỉ số nhân trắc: chiều cao, cân nặng, BMI

Chu vi vòng cánh tay (MAC), lớp mõ dưới da tam đầu cánh tay (TSF), chu vi cơ cánh tay (MAMC), Cơ lực bàn tay (HGS)

Phân loại nguy cơ SDD: SGA-A, SGA-B, SGA-C

2.4. Phương pháp thu thập thông tin. Cân, đo các chỉ số nhân trắc, cơ lực và khám lâm sàng dinh dưỡng. Thu thập thông tin liên quan, các chỉ số xét nghiệm từ hồ sơ bệnh án.

\subsection{Phương pháp xử lý số liệu}

Xử lí số liệu: Xử lí số liệu bằng phần mềm Stata 3.1. Kết quả trình bày theo dạng bảng tần số, tỷ lệ, giá trị trung bình, độ lệch chuẩn.

2.6. Đạo đức nghiên cứu. Nghiên cứu được tiến hành sau khi được Bệnh viện Phổi Trung ương chấp nhận. Đối tượng hoàn toàn tự nguyện tham gia vào nghiên cứu và có quyền rút lui khỏi nghiên cứu khi không đồng ý tiếp tục tham gia vào nghiên cứu, các thông tin cá nhân được đảm bảo bí mật.

\section{KẾT QUẢ NGHIÊN CỨU}

Bảng 1. Thông tin chung về đối tượng nghiên cứu

\begin{tabular}{|c|c|c|c|}
\hline Tuổi & \multicolumn{3}{|c|}{$\begin{array}{c}\text { TB } \pm \text { SD }=67,59 \pm 9,31 \\
\min =40 ; \max =86\end{array}$} \\
\hline \multirow{2}{*}{ Giới } & Nam & 95 & 89.62 \\
\hline & Nữ & 11 & 10.38 \\
\hline \multirow{5}{*}{$\begin{array}{l}\text { Trình độ } \\
\text { học vấn }\end{array}$} & Mù chữ & 4 & 3,77 \\
\hline & Tiếu học & 23 & 21,70 \\
\hline & THCS & 54 & 50,94 \\
\hline & THPT & 18 & 16,98 \\
\hline & $\begin{array}{c}\text { Trung cấp/Cao } \\
\text { đằng/Đại học trở lên }\end{array}$ & 7 & 6,60 \\
\hline \multirow{3}{*}{$\begin{array}{l}\text { Hút thuốc } \\
\text { lá/thuốc } \\
\text { lào }\end{array}$} & Không, chưa từng hút & 18 & 16,98 \\
\hline & Có, đã dừng hút & 80 & 75,47 \\
\hline & Có, vân đang hút & 8 & 7,55 \\
\hline
\end{tabular}

Tuối trung bình của nhóm đối tượng nghiên cứu là 67,59 99,31 tuổi. Tỷ lệ giới tính nam cao gấp gần 9 lần so với tỷ lệ giới nữ. Trình độ học vấn, có $50,94 \%$ chiếm đa số ĐTNC học hết THCS, đối tượng mù chũ chỉ chiếm 3,77\%. Trong số 88 ĐTNC đã và đang hút thuốc lá/thuốc lào có trung bình số năm hút thuốc là 32,06 năm, số năm hút thuốc lớn nhất là 65 năm.

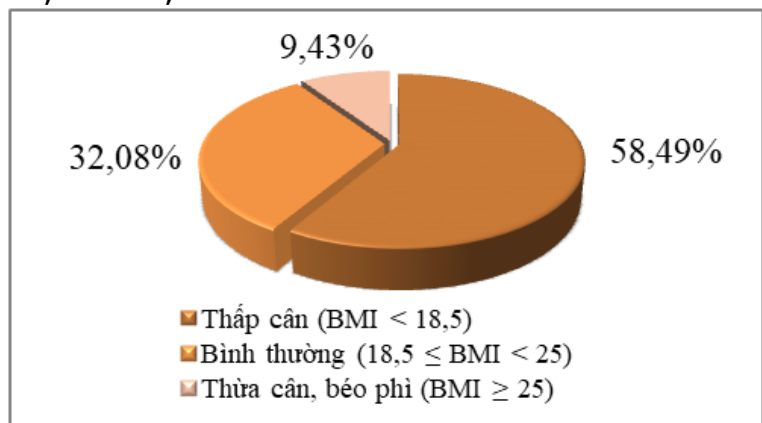

Biểu đồ 1. Chỉ số khối cơ thể (BMI) của ĐTNC

Kết quả nghiên cứu cho thâyy đối tượng có BMI trong giới hạn bình thường $(18,5 \leq \mathrm{BMI}<$ 25) là $32,08 \%$. Đối tượng thấp cân (BMI $<18,5$ ) là $58,49 \%$ và thừa cân, béo phì $(B M I \geq 25)$ là

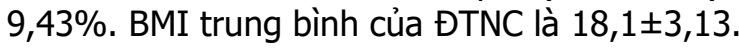

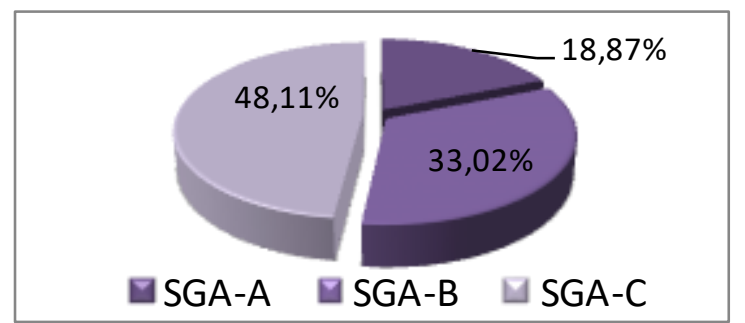

Biểu đồ 2. Tình trạng dinh dưỡng của đối tượng nghiên cúu theo SGA 
Trong 106 ĐTNC có 51 bệnh nhân (48,11\%) được chẩn đoán có tình trạng suy dinh dương nặng (SGA-C), 35 bệnh nhân (33,02\%) được chẩn đoán suy dinh dưỡng mức độ nhẹ hoặc vừa (SGA-B) và 20 bệnh nhân (18,87\%) có tình trạng dinh dương tốt (SGA-A).

Bảng 2. Tình trạng sụt cân không chủ ý trong 6 tháng

\begin{tabular}{|c|c|c|c|c|c|c|c|}
\hline \multirow{2}{*}{$\begin{array}{c}\text { Giảm cân trong 6 } \\
\text { tháng (\%) }\end{array}$} & \multicolumn{2}{|c|}{ Nam } & \multicolumn{2}{c|}{ Nữ } & \multicolumn{2}{c|}{ Tống số } & p-value \\
\cline { 2 - 8 } & $\mathbf{n}_{\mathbf{1}}$ & $\mathbf{\%}$ & $\mathbf{n} \mathbf{2}$ & $\mathbf{\%}$ & $\mathbf{n}$ & $\mathbf{\%}$ & \\
\hline$<5 \%$ & 37 & 38,95 & 7 & 63,64 & 44 & 41,51 & \multirow{2}{*}{$\mathbf{0}, \mathbf{2 8 4}$} \\
\hline $5-10 \%$ & 28 & 29,47 & 1 & 9,09 & 29 & 27,36 & \\
\hline$>10 \%$ & 30 & 31,58 & 3 & 27,27 & 33 & 31,13 & \\
\hline Tống số & $\mathbf{9 5}$ & $\mathbf{1 0 0}$ & $\mathbf{1 1}$ & $\mathbf{1 0 0}$ & $\mathbf{1 0 6}$ & $\mathbf{1 0 0}$ & \\
\hline
\end{tabular}

p: so sánh tỷ lệ, sử dụng Fisher's Exact test

Trong số 106 Đ̇TNC, có 44 chiếm $41,51 \%$ bệnh nhân có tỷ lệ giảm cân trong 6 tháng < $5 \%$ trọng lượng cơ thể, 29 chiếm 27,36\% bệnh nhân có tỷ lệ giảm cân trong 6 tháng từ 5 đến $10 \%$ và 33 chiếm $31,13 \%$ bệnh nhân giảm cân $>10 \%$ trọng lượng cơ thể, sự khác biệt không có ý nghĩa thống kê về nguy cơ SDD ở nam và nữ theo phần trăm giảm cân trong 6 tháng $(p>0,05)$.

Bảng 3. Mối liên quan giữa nhân trắc với $S G A$

\begin{tabular}{|c|c|c|c|c|c|}
\hline Biến số & $\begin{array}{c}\text { Tống số } \\
(\mathbf{n = 1 0 6})\end{array}$ & $\begin{array}{c}\text { SGA-A } \\
(\mathbf{n = 2 0})\end{array}$ & $\begin{array}{c}\text { SGA-B } \\
(\mathbf{n = 3 5})\end{array}$ & $\begin{array}{c}\text { SGA-C } \\
(\mathbf{n = 5 1})\end{array}$ & p-value \\
\hline BMI $\left(\mathrm{kg} / \mathrm{m}^{2}\right)$ & $18,1 \pm 3,1$ & $21,9 \pm 2,3$ & $19,5 \pm 1,9$ & $15,7 \pm 1,8$ & $<0,001$ \\
\hline MAC $(\mathrm{cm})$ & $23,4 \pm 3,2$ & $27,1 \pm 2,2$ & $24,6 \pm 2,2$ & $21,2 \pm 2,2$ & $<0,001$ \\
\hline TSF $(\mathrm{mm})$ & $7,1 \pm 3,8$ & $11,1 \pm 5,2$ & $7,8 \pm 2,8$ & $5,1 \pm 1,7$ & $<0,001$ \\
\hline MAMC (cm) & $21,2 \pm 2,7$ & $23,9 \pm 2,4$ & $22,1 \pm 1,9$ & $19,6 \pm 2,0$ & $<0,001$ \\
\hline Chu vi bắp chân (cm) & $27,4 \pm 3,5$ & $31,1 \pm 2,8$ & $28,7 \pm 2,1$ & $25,1 \pm 2,7$ & $<0,001$ \\
\hline HGS (kg) & $20,2 \pm 7,9$ & $24,3 \pm 6,0$ & $21,8 \pm 8,3$ & $17,5 \pm 7,3$ & 0,0012 \\
\hline
\end{tabular}

p: so sánh trung bình, sử dụng ANOVA-test

Bảng 4 cho thấy tình trạng dinh dưỡng có mối liên hệ tương quan với các chỉ số nhân trắc bao gồm BMI, MAC, TSF, MAMC và chu vi bắp chân: các chỉ số nhân trắc giảm có ý nghĩa thống kê khi tình trạng suy dinh dưỡng nặng dần lên $(p<0,001)$. Đồng thời, cơ lực của ĐTNC cũng giảm dần khi tình trạng suy dinh dưỡng nặng lên $(p<0,01)$.

\section{BÀN LUẬN}

Trong nghiên cứu này đa số người bệnh (88/106 chiếm $83,02 \%)$ có tiếp xúc thường xuyên với khói thuốc lá, thuốc lào (đã từng hút hoặc đang hút thuốc). Hút thuốc lá là nguy cơ cao gây phát triển bệnh viêm phế quản mãn tính và khí phế thũng [2]. Thuốc lá cũng gây ra những thay đổi cấu trúc đối với các nhú dạng nấm của lưỡi, nơi đặt các chồi vị giác [2]. Từ đó làm thay đổi, giảm vị giác của người hút và giảm cảm giác ngon miệng khi ăn. Người hút thuốc có sự rối loạn chức năng phổi và có nhiều triêuu chứng hô hấp hơn những người không hút thuốc lá, tuy nhiên sự nhạy cảm với khói thuốc là khác nhau ở mỗi cá thể.

Tỷ lệ thấp cân trong 106 ĐTNC lên tới $58,49 \%$. Tỷ lê này khá tương đồng với nghiên cứu của Nguyễn Thị Thu Liễu và cộng sự (2018) là $56,7 \%$ [4]. Tỷ lệ này thấp hơn nghiên cứu của
Đinh Thị Phương Thảo [5] là 69,3\%. Sự khác biệt này là do nghiên cứu của các tác giả trên đều có đối tượng nghiên cứu là bệnh nhân bệnh phổi tắc nghẽn mạn tính trong giai đoạn cấp có tình trạng bênh nặng.

Đánh giá TTDD theo SGA có $81,13 \%$ bệnh nhân được đánh giá là suy dinh dưỡng. Kết quả này cao hơn tỷ lệ suy dinh dưỡng ở nghiên cứu của Nguyễn Thanh Hà và cộng sự (2020) là $74,4 \%$ được xác định là bị suy dinh dưỡng [6]. Có sự khác biêt này do đối tượng nghiên cứu của tác giả trên là người bệnh COPD ngoại trú, có tình trạng bệnh ổn định hơn bệnh nhân nội trú bệnh viện. Kết quả nghiên cứu của chúng tôi khá tương đồng với nghiên cứu của Nguyễn Thị Thu Liễu (2018) là $83,4 \%$ bệnh nhân có nguy cơ suy dinh dưỡng (SGA B, C) [4] do ĐTNC của chúng tôi là có sự tương đồng về tình trạng bệnh lý (cùng là bệnh nhân nhập viện nội trú).

Liên quan đến vấn đề giảm cân của đối tượng tham gia nghiên cứu, trong nghiên cứu này có đến $41,51 \%$ ĐTNC giảm <5\%, 27,36\% giảm cân từ 5 đến $10 \%$ và $31,13 \%$ giảm cân $>10 \%$. Kết quả này có sự khác biệt với nghiên cứu của Đinh Thị Phương Thảo là $20,7 \%$ giảm cân $<5 \%$, $32,7 \%$ giảm cân từ $5-10 \%$ và $46,6 \%$ giảm cân trên $10 \%$ trọng lượng cơ thể trong 6 tháng [5]. Nghiên cứu của Pinar Ergün cho kết quả 54\% 
bệnh nhân giảm cân trên 5\% [7]. Trọng lượng cở thể thấp và giảm cân không chủ ý có khả năng tiên đoán cao về tỷ lệ tử vong và bệnh tật ở người cao tuổi. Trong đó các bênh cấp tính và mãn tính là nguyên nhân hàng đầu gây giảm cân không tự chủ [4]

Các chỉ số nhân trắc hoc bao gồm BMI, MAC TSF, MAMC, chu vi bắp chân và HGS đều có giá trị trung bình thấp hơn đáng kể đối với những người có nguy cơ suy dinh dưỡng nặng (SGA-C) và tương đồng với kết quả nghiển cứu của Nguyễn Thanh Hà [6]. Điều này phù hơp với kết quả nghiên cứu của Riviati cho thấy tuổi $>75$ làm tăng nguy cơ có độ bền tay cầm thấp gấp 2,3 lần và suy dinh dưỡng làm tăng nguy cơ độ bền tay cầm thấp lên 1,9 lân [8]. Chức năng cơ kém và gầy mòn là những biểu hiện toàn thân thường gặp ở bệnh nhân COPD. Theo dõi những chỉ số nhân trắc và cơ lực giúp đánh giá hiệu quả của can thiệp dinh dưỡng trên người bệnh [8].

\section{KẾT LUẦN}

Nghiên cứu được tiến hành trên 106 bệnh nhân bệnh phổi tắc nghẽn mạn tính tại khoa Bệnh phổi mãn tính Bệnh viện Phổi Trung ương. Tý lệ thấp cân (BMI < 18,5) là $58,49 \%$ và thừa cân, béo phì (BMI $\geq 25$ ) là 9,43\%. BMI trung

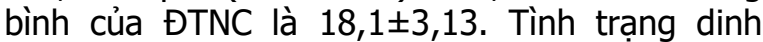
dưỡng của nhóm đối tượng nghiên cứu theo phân loại SGA: 33,02\% suy dinh dưỡng nhe hoặc vừa (SGA-B) và $48,11 \%$ suy dinh dưỡng nặng (SGA-C).

\section{TÀI LIÊU THAM KHẢO}

1. Chronic obstructive pulmonary disease (COPD) (2021). Accessed April 30, 2021. https://www.who.int/news-room/factsheets/detail/chronic-obstructive-pulmonarydișease-(copd)

2. Đố Thị Lương. Tình trang dinh dưỡng ở bệnh nhân bềnh phối tắc nghẽn man tính giai đoan ổn định và một số yếu tố liên quan tại Bệnh viện Bạch Mai năm 2015. Published online 2016

3. Schols AM, Ferreira IM, Franssen FM, et al (2014). Nutritional assessment and therapy in COPD: a European Respiratory Society statement. Eur Respir J. 2014;44(6):1504-1520. doi:10.1183/ 09031936.00070914

4. Nquyễn Thị Thu Liễu, Hoàng Thị Ngọc Anh, Đố Nam Khánh (2018). Tình trạng dinh dưỡng và một số yếu tố liên quan của người bênh mắc bệnh phổi tắc nghẽn mạn tính tại Bệnh viện Phổi Trung ương năm 2018. Tạp Chí Nghiên Cứu Học. 2016;120 (4):52-58.

5. Đinh Thi Phương Thảo. Khảo sát tình trang dinh dưỡng ở bệnh nhân đợt cấp bệnh phổi tắc nghẽn mạn tính tại Bệnh viện Bạch Mai năm 2014. Published online 2015.

6. Nguyen Ha Thanh, Pavey TG, Collins PF, Nguyen NV, Pham TD, Gallegos D. (2020). Effectiveness of Tailored Dietary Counseling in Treating Malnourished Outpatients with Chronic Obstructive Pulmonary Disease: A Randomized Controlled Trial. J Acad Nutr Diet;120(5):778791.e1. doi:10.1016/j.jand.2019.09.013

7. Ergün $P$, Turay UY, Aydoğdu M, et al (2003). Nutritional status of COPD patients with acute exacerbation. Tuberk Ve Toraks;51(3):239-243.

8. Riviati N, Setiati S, Laksmi PW, Abdullah M (2017). Factors Related with Handgrip Strength in Elderly Patients. Acta Medica Indones;49(3):215-219.

\title{
TIẾN TRIỂN CỦA SCHÖNLEIN - HENOCH THỂ BỤNG Ở TRẺ EM
}

\author{
Nguyễn Thị Hồng Hạnh ${ }^{1}$, Nguyễn Thị Diệu Thúy ${ }^{1}$ \\ Lê Huyền Trang ${ }^{2}$, Phan Văn Nhã ${ }^{1}$
}

\section{TÓM TẮT}

Henoch-Schönlein pupura (HSP) là bênh viêm mạch hệ thống không rõ căn nguyên có tổn thương các mạch nhỏ do lắng đọng phức hợp miễn dịch IgA, biểu hiện chủ yếu trên da, ruột, thận, khớp. Triệu chứng tiêu hóa găp phổ biến và là nguyên nhân chủ yếu khiến người bệnh nhập viện. Bệnh nhìn chung có tiên lượng tốt, tuy nhiên một số trường hợp tiến triển nặng. Mục tiêu: Nghiên cứu được tiến hành nhằm

\footnotetext{
${ }^{1}$ Đại học Y Hà nọi

2Bềnh viện Nhi Trung ương

Chịu trách nhiệm chính: Nguyễn Thị Diệu Thúy

Email: nguyendieuthuyhmu@gmail.com

Ngày nhận bài: 9.8.2021

Ngày phản biên khoa hoc: 1.10 .2021

Ngày duyệt bài: 11.10.2021
}

mô tả đặc điểm lâm sàng, cận lâm sàng và đánh giá tiến triển bênh HSP thể bung. Phương pháp: 134 trẻ được chẩn đoán HSP thể bụng lần đâu điều trị nội trú tai viên Nhi trung ương từ tháng 7/2020 đến tháng 6/2021. Đây là nghiên cứu một loat ca bệnh. Kểt quả: Tuổi trung vị của trẻ là 7 tuổi. Biểu hiên đau bunng gặp ở $100 \%$ trường hợp. Triệu chứng tiểu hóa xuất hiển trước phát ban găp ở $35,8 \%$ các trường hợp. Các biến chứng bao gồm: xuất huyết tiêu hóa (44\%), lồng ruột, viêm tụy cấp. Nhìn chung các tổn thương trong HSP đều có tiến triển tốt, tự khỏi trong vòng 1vài tuần đến 1 tháng. Tổn thương thận ở nhóm HSP thể bụng đơn thuần xuất hiện sau nhập viện 1 tuần đến 1 tháng, tỷ lê này giảm dần ở tháng thứ 3. Tái phát xảy ra ở 28,4\% bệnh nhân. Kết luận: Hầu hết bênh nhân HSP tiến triển tốt, các triệu chưưng tự hồi phục. Cần tiếp tục theo dõi nước tiểu ở tất cả các bệnh nhân mắc HSP để theo dõi tổn thương thận. 